\title{
Acute effect of aerobic and resistance exercises on cardiovascular and neuromuscular responses in normotensive
}

\author{
Roberto José Ruiz (1), Paulo Fernandes Pires (1), Elisa Bizetti Pelai (1), Ester Moreira de Castro (2), \\ Fabiana Foltran Mescollotto ${ }^{(3)}$, Marlene Aparecida Moreno ${ }^{(4)}$, Delaine Rodrigues Bigaton ${ }^{(4)}$
}

\begin{abstract}
Introduction: the literature report the effect of different types of exercise (aerobic and resisted) on cardiovascular and neuromuscular behavior after exercise. Objective: the objective of this study was to verify the acute effect after a resisted or aerobic exercise session on arterial pressure (BP), heart rate (HR), muscular strength and electromyography (EMG) activity of the rectus femoris (RF), vastus lateralis (VL) and vastus medialis (MV) in normotensive individuals. Method: the study included eight men $(27.3 \pm 3.1 \mathrm{years}, 76.4 \pm 9.7 \mathrm{~kg}$, $1.80 \pm 0.10 \mathrm{~m}, 24.3 \pm 1.6 \mathrm{~kg} / \mathrm{m}^{2}$ ), physically active individuals who randomly performed an aerobic exercise session (treadmill, $30 \mathrm{~min}$, $60-70 \%$ of the reserve heart rate), or a resisted exercise session (nine exercises, three sets, 70\% 1RM, 8 - 12 repetitions). The BP, HR, EMG and muscle strength, were analyzed at rest before exercise and for $60 \mathrm{~min}$ after exercise. Results: as a result, systolic BP after the exercises (aerobic and resisted) remained lower than the pre-exercise rest values, with 30,45 and 60 min $(p<0.05)$ of recovery. On the other hand, the diastolic BP was lower after resistive exercise in all periods of recovery $(p<0.01)$ in relation to pre-exercise. HR values remained elevated after aerobic and resisted exercise, in all recovery periods $(p<0.05)$. Muscle strength and electromyography activity did not show significant differences after exercise. Conclusion: independently of the exercise type, occurs post-exercise hypotension $(\mathrm{PEH})$, increase the HR during the recovery period and reestablishment of muscle strength and myoelectric activity of muscles compared to pre-exercise.
\end{abstract}

Keywords: Exercise; Blood Pressure; Heart Rate

\section{INTRODUCTION}

Post exercise hypotension (PEH) is defined as the reduction of the blood pressure (BP) promoted by exercise. It is characterized by the decrease of $\mathrm{BP}$ below the rest values after a dynamic exercise session, both in normotensive ${ }^{(1)}$ and hypertensive ${ }^{(2)}$. To achieve PEH are recommended both aerobic and resisted exercises.

Casonatto and Polito ${ }^{(3)}$ in a systematic review, found that after an aerobic exercise session, $\mathrm{PEH}$ occurred in studies with intensities of 50 to $80 \%$ of heart rate reserve $\left(\mathrm{HR}_{\text {res }}\right)$ and varying the duration of the exercise between 15 and 60 minutes. Anunciação and Polito ${ }^{(4)}$ and Dutra et al., ${ }^{(5)}$ in their systematic reviews, analyzed the effect of a resisted exercise session on PEH and concluded that the resisted exercise promotes subacute BP reduction in normotensive and hypertensive patients. Anunciação et al. ${ }^{(6)}$; Abrahin et al. ${ }^{(7)}$ and Leal et al. ${ }^{(8)}$ indicate that BP reduction after a resisted exercise session seems feasible, especially in hypertensive individuals, who are the major beneficiaries of PEH.
Considering that the mechanisms related to PEH may be different between aerobic and resisted activity and that physical exercise for health include both ${ }^{(9)}$, it becomes important to know the cardiovascular behavior after such efforts. In addition, further investigations involving resisted exercise under physiological and neuromuscular aspects are still little explored in the literature, since studies of the PEH relationship and neuromuscular adaptations after a resisted exercise session were not found in the researched literature. In view of the above, it is hypothesized that aerobic exercise provides greater magnitude and duration of PEH when compared to resisted exercise, and that resisted exercise promotes greater alteration of musculoskeletal variables, such as a decrease in muscle strength production and electromyographic (EMG) activity.

The objective of the study was to verify the acute effect after a resisted or aerobic exercise session on blood pressure (BP), heart rate (HR), lower limb muscle strength and

Corresponding Author: Delaine Rodrigues Bigaton, Av. Jaime Pereira 3701, Bairro Ondas, Piracicaba - São Paulo (SP), Brazil - CEP: $13403-800$ -

Telephone: +55 (19) 3124-1558/99787-2013-E-mail: drodrigues@unimep.br

4 Professor of the Post-Graduation Program in Sciences of the Human Movement in the Universidade Metodista de Piracicaba (UNIMEP) - Piracicaba (SP), Brazil. Full list of author information is available at the end of the article

Financial support: The authors declare that there was financial support by "Coordenação de Aperfeiçoamento de Pessoal de Nível Superior (CAPES)." 
EMG activity of the rectus femoris muscle (RF), vastus lateralis $(\mathrm{VL})$ and vastus medialis (VM) in normotensive individuals.

\section{MATERIAL AND METHODS}

This is a cross-sectional observational study, in which eight normotensive men (Blood Pressure less than 140/90 mm Hg) participated, with at least one year of experience in aerobic and resisted training, non-smokers, without diagnosed heart and/or metabolic diseases. The study was approved by the Research Ethics Committee of the institution (62098916.7.0000.5507) and followed the guidelines of Resolution 466/12 of the National Health Council, about research with humans.

Exclusion criteria were the use of chronotropic or inotropic substances and musculoskeletal and/or neuromuscular limitations/dysfunctions that made the exercise impossible.

\section{Experimental procedure}

To select the sample, all subjects answered the physical activity questionnaire (PAR-Q) to detect possible cardiovascular risk factors or contraindications to exercise practice. Being able to participate in the study, they performed anthropometric evaluation of blood pressure (BP) and resting heart rate (HR). The sample was submitted to the continuous and progressive maximal exercise test in the treadmill (Movement, RT 250), following the protocol of Ellestad et al., ${ }^{(10)}$ to determine the maximum oxygen consumption $\left(\mathrm{VO}_{2 \text { peak }}\right)$ and the maximum HR ( $\left.\mathrm{HR}_{\mathrm{Max}}\right)$. Before the beginning of the tes, the $\mathrm{HR}_{\text {Max }}$ was estimated by the equation proposed in the study of Shargal et al. ${ }^{(11)}$. The test was composed of stages of 3 minutes, being started with speed of $2.7 \mathrm{~km} / \mathrm{h}$ and inclination of $10 \%$. At each stage, was added $1.3 \mathrm{~km} / \mathrm{h}$ at the speed and $2 \%$ in the inclination, until the exhaustion or appearance of limiting signs and symptoms. The $\mathrm{HR}_{\text {Max }}$ was consider the higher $\mathrm{HR}$ obtain during the test or when reached the estimated $\mathrm{HR}$, being used to calculate the training zone by $H R$ reserve $\left(H_{\mathrm{res}}\right)^{(12)}$.

To determine the load of the resisted exercise, a maximal repetition test $(1 \mathrm{MR})$ was performed for each activity. The initial load was determined subjectively, indicated by the volunteer himself, who made 3 attempts with an interval of 5 min between them ${ }^{(13)}$, in the exercises: bench press, leg curl, rowing machine, horizontal leg press, triceps pulley, extension chair, developing machine, seated calf and biceps machine.

The order of the exercises (aerobic or resisted) was determined by randomization. All volunteers performed the two exercises following the cross-over design, and the exercises were performed on separate days and separated with a minimum interval of 48 hours.

The aerobic exercise session was characterized by $35 \mathrm{~min}$ of total duration ( 3 min of warm-up, 30 min with intensity of $60-70 \%$ of heart rate reserve and $2 \mathrm{~min}$ of recovery). The resisted exercise session consisted of the following exercises: bench press, leg curl, rowing machine, horizontal leg press, triceps pulley, extension chair, developing machine, seated calf and biceps machine, performed in 3 sets of 8-12 repetitions with intensity of $70 \%$ of $1 \mathrm{MR}$ and recovery interval between the series of $1 \mathrm{~min}$ and 30 seconds, was oriented to subjects not to perform Valsalva maneuver. The choice of volume and intensity of aerobic exercise and resistance exercise to trigger $\mathrm{PEH}$ was based on information available in the literature ${ }^{(1,3,14)}$.

The assessment of $\mathrm{BP}, \mathrm{HR}$, strength and electromyographic activity was performed before and after each exercise session (aerobic and resistance).

Immediately after the end of the exercise sessions, the participants were taken to the same chair in which the pre-exercise measures were taken and were seated without verbal and/or gestural communication for 60 minutes for the measurement of the cardiovascular and neuromuscular variables post- effort.

\section{Measurement of blood pressure and heart rate}

In order to measure systolic BP (SBP) and diastolic BP (DBP), the automatic device Omron HEM-7200 (EUA) was used and the recommendations of the "VII Diretrizes Brasileiras de Hipertensão" was followed ${ }^{(15)}$. The BP was evaluated before the beginning of the exercises and during the 60 minutes after the end of the exercises (aerobic or resisted). Before the first BP measurement the subjects remained seated for $10 \mathrm{~min}$, and after that time two BP measurements were performed with a 2-min interval, considering as pre-exercise value the mean of both. After aerobic or resisted exercise (post-exercise), the BP was measured over $60 \mathrm{~min}$ with intervals of $15 \mathrm{~min}$, making a total of five records: 0 (immediately after exercise), $15,30,45$ and $60 \mathrm{~min}$.

HR was assessed before and after exercise by an electronic cardiofrequency (Polar, Finland) just before BP measurements. The delta measurement of recovery $H R$ of 60 seconds (FCR $60 \mathrm{~s}$ ), obtained by the subtraction of HR at the end of the exercise by the one found after 1 minute of recovery, was performed with the subjects seated in a chair after the aerobic session and seated in the machine itself in the resisted exercise session.

Participants were previously advised not to drink caffeine for at least 72 hours before each session, not to perform any type of vigorous physical activity, not to drink alcoholic drinks in the 24 hours prior to the days of collection and to have made a light meal for at least 3 hours before the experiments.

\section{Analysis of Strength and Electromyography}

Muscle strength of the dominant lower limb was assessed by the MM-100 model load cell (Kratos ${ }^{\circledR}$, São Paulo, SP, Brazil), connected to the "BIO-EMG 1000-Lynx Electronic Technology Ltd" signal acquisition system. The load cell remained parallel to the floor, attached to the wall and fixed to the volunteer's ankle. Muscle strength was collected concomitantly with electromyographic activity. For this collection was used 
the "BIO-EMG 1000-Lynx Electronic Technology Ltd" with a analog-to-digital converter with 16-bit resolution and $2000 \mathrm{~Hz}$ sampling frequency following the recommendations of the International Society of Electrophysiology and Kinesiology (ISEK).

For placement of the electrodes was performed tricotomy in the region and cleaning of the skin with alcohol $70 \%$. The electrodes were placed in the muscles: rectus femoris muscle (RF), $50 \%$ of the line between the anterior superior iliac spine and the superior border of the patella; vastus lateralis $(V L), 2 / 3$ of the line between the iliac spine and the lateral border of the patella, vastus medialis (VM), $80 \%$ of the line between the iliac spine and joint space in front of the medial ligament and the reference electrode positioned on the patella, according to the recommendations of the SENIAM ${ }^{(16)}$.

In order to collect the electromyographic signal the volunteer remained seated in a chair without resting his feet on the floor. The electromyographic signal and strength were collected three times during the maximal isometric voluntary contraction (MIVC) of knee extension for 5 seconds, with an interval of 3 minutes between them. The collections were performed pre-exercise and late post-exercise (60 min after exercise).

\section{Electromyographic Signal Processing}

The signals were analyzed offline by the Matlab ${ }^{\circledR}$ 8.3 software (The MathWorks Inc., Natick, Massachusetts, USA), in which a 4th order Butterworth type digital filter with zero phase delay, with high pass of $10 \mathrm{~Hz}$ and low pass of $400 \mathrm{~Hz}$ was applied. The first and fifth second of each EMG signal was eliminated, being analyzed 3 s of each collected signal.

The analysis was performed: 1) in the frequency domain, to obtain the values of average frequency $(\mathrm{Hz})$ of the power spectral density of the EMG signal evaluated using the Fast Fourier Transform (FFT) algorithm with overlap of $50 \%$ (Hamming window processing) and 2) in the amplitude domain, to obtain the values of the integral of the electromyographic signal (IEMG), through a root mean square (RMS) window of 150 ms with later integration.

\section{Statistical analysis}

To statistical analysis was used the SPSS 20.0 software, the Shapiro-Wilk test was used to evaluated the normality of data and the Levene test was used to the homogeneity of variances. When the data was normal, the Student's t-test for dependent and independent samples were used in the comparison of the neuromuscular variables, when the data were not normal, were used their corresponding Mann-Whitney. As the data were homogeneous, the three-way ANOVA (resisted $x$ aerobic $x$ monitoring time) with repeated measurements was used for intra and inter group comparisons in cardiorespiratory variables. When necessary, the Tukey post-hoc test was used to verify the differences. In all cases, a $P$ value of less than 0.05 was considered statistically significant.

\section{RESULTS}

To characterize the sample, the results of anthropometric and cardiorespiratory assessments are listed in Table 1.

The results of the means of SBP, DBP and HR in the pre-exercise, post-immediate and during 60 minutes of recovery after the different types of exercises are listed in Table 2. The SBP values after the resisted and aerobic exercises in the 30, 45 and 60 minutes of antecedent when compared

Table 1. Characterization of the sample, age, anthropometric and cardiorespiratory variables.

\begin{tabular}{cc}
\hline \multicolumn{1}{c}{ Characterization of the sample $(\mathrm{n}=8)$} \\
\hline Variables & mean \pm standard deviation \\
\hline Age(years) & $28.7 \pm 7.3$ \\
Body mass $(\mathbf{k g})$ & $89.3 \pm 10.1$ \\
Height $(\mathrm{m})$ & $1.79 \pm 0.3$ \\
BMI $\left(\mathbf{k g} / \mathrm{m}^{2}\right)$ & $27.6 \pm 2.5$ \\
\hline Time $(\mathrm{min})$ & Ergometric Test \\
\hline HRmax $(\mathbf{b p m})$ & $13.3 \pm 0.5$ \\
VO $_{\text {2peak }}(\mathrm{ml} / \mathrm{kg} / \mathrm{min})$ & $188.7 \pm 7.3$ \\
\hline
\end{tabular}

Note: the values are presented in mean \pm standard deviation. BMI: body mass index; HRmax: maximum heart rate; $\mathrm{VO}_{2 \text { peak }}$ : peak oxygen consumption.

Table 2. Cardiovascular variables, systolic blood pressure (SBP), diastolic blood pressure (DBP), pre-exercise heart rate (HR), immediately after exercise $(0 \mathrm{~min}$ ) and during $60 \mathrm{~min}$ after the end of both types of exercises (aerobic and resisted), and variation delta (HRR60s).

\begin{tabular}{lcccc}
\hline Variables & $\begin{array}{c}\text { SBP }(\mathrm{mmHg}) \\
\text { Mean } \pm \text { SD }\end{array}$ & $\begin{array}{c}\text { DBP }(\mathrm{mmHg}) \\
\text { Mean } \pm \text { SD }\end{array}$ & $\begin{array}{c}\text { HR }(\mathrm{bpm}) \\
\text { Mean } \pm \text { SD }\end{array}$ & $\begin{array}{c}\text { HRC60s } \\
(\mathbf{b p m}) \Delta\end{array}$ \\
\hline AEROBIC & & & & $37.3 \pm 3.7$ \\
Pre-exercise & $121.8 \pm 9.7$ & $67 \pm 11.2$ & $66.8 \pm 3.9$ & \\
0 min & $129.1 \pm 10.3^{\dagger}$ & $74 \pm 10.2^{+}$ & $95.2 \pm 9.2^{\dagger}$ & \\
15 min & $121.6 \pm 11.3$ & $68.7 \pm 9.7$ & $83.6 \pm 5.2^{\dagger}$ & \\
30 min & $117.8 \pm 8.4^{*}$ & $68.2 \pm 10.3$ & $79.5 \pm 5.4^{\dagger}$ & \\
45 min & $114.5 \pm 11.7^{*}$ & $66.6 \pm 10.5$ & $78.2 \pm 5.5^{\dagger}$ & \\
60 min & $115.3 \pm 10.7^{*}$ & $66.7 \pm 10.4$ & $74.7 \pm 4.4^{\dagger}$ &
\end{tabular}

RESISTED

$21.6 \pm 1.9 \ddagger$

$\begin{array}{lrrr}\text { Pre-exercise } & 121.5 \pm 8.3 & 67.2 \pm 8.5 & 69.2 \pm 9.3 \\ 0 \mathrm{~min} & 132 \pm 15.3^{\dagger} & 62.2 \pm 8.4^{*} \ddagger & 101.5 \pm 15.2 \dagger \\ 15 \mathrm{~min} & 120.1 \pm 10.2 & 58.6 \pm 10.2^{*} \ddagger & 85.6 \pm 11.9+ \\ 30 \mathrm{~min} & 114.8 \pm 7.3^{*} & 59.1 \pm 6.5^{*} \ddagger & 81.2 .2 \pm 13.4 \dagger \\ 45 \mathrm{~min} & 117.5 \pm 10.6^{*} & 62.8 \pm 10.1^{*} & 77.5 .2 \pm 10.2+ \\ 60 \mathrm{~min} & 116.1 \pm 11.5^{*} & 63.4 \pm 10^{*} & 77.2 \pm 10 \dagger\end{array}$

Note: $*$ Significant decrease $(p<0.05)$ in relation to pre-exercise; + significant increase $(p<0.05)$ in relation to pre-exercise; $¥$ significant difference $(p<0.05)$ in relation to aerobic; HRR60s: delta of the HR of recovery after the exercise. 
to the pre-exercise moment $(p<0.05)$. The DBP did not present significant difference after the aerobic exercise and recovery period in relation to the initial pre-exercise values. However, there was a significant difference in relation to resisted exercise, DBP values remained lower than pre-exercise values in all the recovery periods $(p<0.01)$. The results also showed significant differences after the exercise in the DBP in relation to the types of exercise and recovery periods. The DBP in the resisted exercise was lower when compared to the aerobic in the 0,15 and $30 \mathrm{~min}$ of recovery $(p<0.05)$.

The HR remained elevated after resisted and aerobic exercise, in all recovery periods $(p<0.01)$ with relation to the pre-exercise values. Whereas the HRR 60s was higher after the aerobic exercise $(p<0.01)$ in relation to the resisted exercise.

The results of neuromuscular, maximal strength and electromyographic signals variables, in the amplitude (IEMG) and frequency (Fmed) domain, pre-exercise and $60 \mathrm{~min}$ of recovery after the different types of exercises are in the Table 3 and 4 . Regarding the values of maximum strength, IEMG and Fmed, no significant differences were observed after the two types of exercise and recovery period in relation to the pre-exercise values for all muscles evaluated.

Table 3. Neuromuscular, integral of the electromyographic signal (IEMG) and median frequency (Fmed) variables of the rectus femoris (RF), vastus medialis (VS) and vastus lateralis (VL) muscles in the pre-exercise and after 60 minutes at the end of the exercises (aerobic or resisted).

\begin{tabular}{|c|c|c|c|}
\hline Variables & $\begin{array}{l}\text { IEMG(RF) }(\mu \mathrm{V} / \mathrm{s}) \\
\text { Mean } \pm \text { SD }\end{array}$ & $\begin{array}{l}\text { IEMG(VM) }(\mu \mathrm{V} / \mathrm{s}) \\
\text { Mean } \pm \text { SD }\end{array}$ & $\begin{array}{c}\text { IEMG(VL) }(\mu \mathrm{V} / \mathrm{s}) \\
\text { Mean } \pm \text { SD }\end{array}$ \\
\hline \multicolumn{4}{|l|}{ AEROBIC } \\
\hline pre-exercise & $395.11 \pm 222.4$ & $1049 \pm 526.9$ & $532.37 \pm 183.9$ \\
\hline $60 \mathrm{~min}$ & $386.36 \pm 158.3$ & $795.09 \pm 301.5$ & $590.41 \pm 254.3$ \\
\hline \multicolumn{4}{|l|}{ RESISTED } \\
\hline pre-exercise & $446.32 \pm 248$ & $1004.4 \pm 533.5$ & $633.5 \pm 312.4$ \\
\hline \multirow[t]{2}{*}{$60 \mathrm{~min}$} & $415.67 \pm 222.1$ & $1001.9 \pm 571.2$ & $667.15 \pm 432.2$ \\
\hline & Fmed(RF) (Hz) & Fmed(VM) (Hz) & Fmed(VL) (Hz) \\
\hline \multicolumn{4}{|l|}{ AEROBIC } \\
\hline pre-exercise & $75.12 \pm 6.8$ & $65.05 \pm 7.91$ & $66.6 \pm 7.7$ \\
\hline $60 \mathrm{~min}$ & $73.28 \pm 8.39$ & $74.94 \pm 14.9$ & $72.09 \pm 16.1$ \\
\hline \multicolumn{4}{|l|}{ RESISTED } \\
\hline pre-exercise & $76.45 \pm 10.6$ & $66.87 \pm 9.3$ & $65.75 \pm 6.01$ \\
\hline $60 \mathrm{~min}$ & $74.86 \pm 8.6$ & $66.04 \pm 8.67$ & $75.15 \pm 19$ \\
\hline
\end{tabular}

Table 4. Neuromuscular variable, maximal muscle strength in the pre-exercise and after 60 minutes at the end of the exercises (aerobic and resistance).

\begin{tabular}{lll}
\hline \multicolumn{1}{c}{ Variables } & $\begin{array}{c}\text { AEROBIC } \\
\text { Mean } \pm \text { SD }\end{array}$ & $\begin{array}{c}\text { RESISTED } \\
\text { Mean } \pm \text { SD }\end{array}$ \\
\hline Maximal strength $(\mathrm{Kg})$ & & \\
pre-exercise & $78.8 \pm 11.9$ & $79.1 \pm 14.9$ \\
60 min & $77.4 \pm 9.89$ & $78.8 \pm 15.6$ \\
\hline
\end{tabular}

\section{DISCUSSION}

The results obtained in the present study demonstrated the occurrence of PEH in normotensive men after aerobic and resisted exercise. MacDonald et al. ${ }^{(17)}$ observed a decrease in SBP during 60 minutes, after performing 15 minutes of exercise on a cycle ergometer with $\mathrm{VO}_{2}$ max intensity of $65 \%$, similarly, Jones et al. ${ }^{(18)}$ also verified a decrease in the SBP after 30 minutes of exercise on a cycle ergometer with $\mathrm{VO}_{2}$ peak intensity of $70 \%$, however, found no decrease in DBP after aerobic exercises. On the other hand, Fisher et al. ${ }^{(19)}$ analyzing the $\mathrm{PEH}$ effect in resisted exercise ( 5 exercises, 3 sets, 15 repetitions at 50\% 1RM), observed only a decrease in SBP and no decrease in DBP.

Some studies available in the literature have pointed out that BP can be reduced after a single exercise session ${ }^{(20,21)}$, however, the SBP seems to be more sensitive to the modifications imposed by the exercise when the sample are composed of normotensive, as well as in the present study. In this way, many studies involving aerobic and resisted exercise $^{(1,19,21-22)}$ in normotensive patients, identified PEH only in SBP, with little change in DBP for the resisted exercise. However, in the Figueredo et al. ${ }^{(20)}$ observed that after the resisted exercise of 70\%1RM occurred $\mathrm{PEH}$ in the DBP, this fact was confirmed in the present study, in which the DBP response was altered in the resisted exercise and the magnitude of this response was greater than in the aerobic exercise.

In relation to $\mathrm{HR}$, was observed a significant increase after the aerobic and the resisted exercise, which can be explained by the compensatory increase in cardiac output and HR post-exertion, leading to a possible cardiovascular adjustment to compensate for the decrease in peripheral vascular resistance in aerobic exercise ${ }^{(23)}$.

However, some evidence shows a reduction in cardiac output after resisted exercise, followed by increased peripheral vascular resistance and $H R{ }^{(24)}$. These results suggest that $\mathrm{HR}$ increases to provide compensatory adjustments in the baroreflex system, since after exercise there is a decrease in $\mathrm{BP}$ and an increase in HR to compensate for this decrease in $\mathrm{BP}$, in agreement with the results of Ruiz et al. ${ }^{(21)}$ that verified an increase in the HR after aerobic and resisted exercise.

Even with similar results in post-exercise hypotensive response, aerobic and resisted activities should have differentiated mechanisms. In the present study, the differentiation in the vagal behavior between activities was verified through the analysis of the HRR60s, which showed greater amplitude in aerobic training. These data suggested that the HR recovery was accelerated after aerobic exercise, suggesting greater sympathetic discharge in the activities of the resisted exercises ${ }^{(21)}$.

Regarding the neuromuscular analyzes, no significant changes were observed when comparing pre-exercise data with those obtained after 60 minutes at the end of the exercises (aerobic or resisted). The findings of the present 
study corroborate with those of McCaulley et al. ${ }^{(25)}$, in which the authors did not observe changes in quadriceps muscle strength (MIVC) and IEMG (RF and VM muscles), after $60 \mathrm{~min}$ recovery after squatting exercises in relation to pre-exercise. On the other hand, Baretta ${ }^{(26)}$ analyzing the 15 min effect of sit-up exercise, observed that $20 \mathrm{~min}$ of recovery was sufficient to re-establish the electromyography activity of the $\mathrm{RF}, \mathrm{MV}$ and $\mathrm{VL}$ muscles, but observed a reduction in muscle strength (knee extension (MIVC)) pre-exercise. Similarly, Izquierdo et al. ${ }^{(27)}$ analyzed 30 min of recovery, after leg-press exercise ( 5 series and 10 maximal repetitions (MR)) and observed a decrease in the muscular strength (knee extension $(\mathrm{CVMI})$ ), but the electromyographic behavior of the Fmed of the RF, VM and VL muscles remained the same in relation to pre-exercise.

Despite the interesting results of the aforementioned studies, the protocol used was different from the present study, since the authors observed the neuromuscular behavior of only one type of exercise, not in relation to a resisted or aerobic exercise session, another difference is in recovery time which was lower than in the present study. Thus, further studies would be required using an exercise session for comparison.

Some limitations were found and deserved comments, autonomic function tests that could be associated with the cardiovascular behavior after exertion were not performed. Another limitation was the reduced number of volunteers, which may have reduced the power of the statistical tests of the study.

With the findings of the present study, it can be suggested that both types, aerobic and resisted, can be used in the prescription of physical exercise for the prevention of the development of hypertension and/or maintenance of BP in normotensive men. Therefore, health and fitness professionals could adopt these training programs. However, further studies with hypertensive individuals would be important to evaluate the cardiovascular and neuromuscular responses in this population.

\section{CONCLUSION}

Through the methodology used, it is concluded that both aerobic and resistive exercise promote $\mathrm{PEH}$ and increase of HR. However, both exercises did not promote alteration of musculoskeletal variables. Therefore, the initial hypotheses of the study were rejected.

\section{AUTHOR'S CONTRIBUTION}

RJR: acquisition of data, statistical analysis and writing of the manuscript; PFP: acquisition and processing of data; EBP and EMC: acquisition of data; FFM: acquisition of data and revision of the manuscript; MAP: co-orientation and revision of the manuscript; DRB: study orientation and revision of the manuscript.

\section{CONFLICTS OF INTEREST}

The authors declare that there are no conflicts of interest.

\section{AUTHOR DETAILS}

${ }^{1}$ Doctor's degree student in Sciences of the Human Movement in the Universidade Metodista de Piracicaba (UNIMEP) - Piracicaba (SP), Brazil. 2- Master's degree student in Sciences of the Human Movement in the Universidade Metodista de Piracicaba (UNIMEP) - Piracicaba (SP), Brazil. 3- PhD student in Sciences of the Human Movement in the Universidade Metodista de Piracicaba (UNIMEP) - Piracicaba (SP), Brazil.

\section{REFERENCES}

1. Simão R, Fleck SJ, Polito M, Monteiro W, Farinatti P. Effects of resistance training intensity, volume, and session format on the postexercise hypotensive response. J Strength Cond Res. 2005;19(4):853-8.

2. Melo CM, Alencar Filho AC, Tinucci T, Mion D Jr, Forjaz CL. Post-Exercise Hypotension Induced by Low-Intensity Resistance Exercise in Hypertensive women Receiving Captopril. Blood Pressure Monitoring. 2006;11(4):183189.

3. Casonatto J, Polito MD. Post-exercise hypotension: a systematic review. Rev Bras Med Esportev 2009;15(2):151-57.

4. Anunciação PG, Polito MD. A Review on Post-Exercise Hypotension in Hypertensive Individuals. Arq Bras Cardiol 2009; 96(4):425-426.

5. Dutra MT, Lima RM, Mota LM, Alves de Oliveira PF, Leão Veloso JH. Hipotensão pós-exercício resistido: uma revisão da literatura. Rev Educ Fis/UEM. 2013;24(1):145-157

6. Anunciação PG, Farinatti PT, Goessler KF, Casonatto J, Polito MD. Blood pressure and autonomic responses following isolated and combined aerobic and resistance exercise in hypertensive older women. Clin Exp Hypertens. 2016;38(8)710-14.

7. Abrahin O, Rodrigues RP. Active intervals during high-intensity resistance exercises enhance post-exercise hypotension in hypertensive women controlled by medications. Isokinetics and Exercise Science 2016; 24(5):141-147

8. Leal VD, Destro DS, Vasconcelos AP, Cardozo DC. Influência do número de séries sobre a resposta da pressão arterial após uma sessão de treinamento de força em mulheres idosas hipertensas. RBPFEX. 2017;11(64):12-19.

9. Pescatello LS, Franklin BA, Fagard R, Farquhar WB, Kelley GA, Ray CA. American College of Sports Medicine position stand. Exercise and hypertension. Med Sci Sports Exerc. 2004;36(3):533-53.

10. Ellestad MH, Allen W, Wan MCK, Kemp GL. Maximal treadmill stress testing for cardiovascular evaluation. Circulation. 1969;39(4):517-22.

11. Shargal E, Kislev-Cohen R, Zigel L, Epstein S, Pilz-Burstein R, Tenenbaum G. Age-related maximal heart rate: examination and refinement of prediction equations. J Sports Med Phys Fitness. 2015;55(10):1207-18.

12. Karvonen MJ, Kentala E, Mustala O. The effects of training on heart rate: a longitudinal study. Ann Med Exper Fenn. 1957;35(3):307-15.

13. Menezes AL, Santana FS, Soares AHG, Souza BCC, Souza DJC, Santos MA, et al. Validação das equações preditivas de uma repetição máxima varia de acordo com o exercício realizado em adultos jovens treinados. Revista Brasileira de Atividade Física e Saúde 2013; 13:95-104.

14. Macdonald JR. Potential causes, mechanisms, and implications of postexercise hypotension. J of Human Hypertension. 2002;16(4):225-236.

15. Malachias MVB, Souza WKSB, Plavnik FL, Rodrigues CIS, Brandão AA, Neves MFT, et al. 7ạ Diretriz Brasileira de Hipertensão Arterial. Arq Bras Cardiol. 2016;107(3):1-83.

16. Hermens DH, Freriks B. European recommendations for surface electromyography: results of the Seniam project. Enschede (The Netherlands): Seniam/Biomed II/ European Union; 1999. Disponível em: www.seniam.org

17. MacDonald JR, MacDougall JD, Interisano SA, Smith KM, McCartney N, Moroz JS, et al. Hypotension following mild bouts of resistance exercise and submaximal dynamic exercise. Eur J Appl Physiol Occup Physiol. 1999;79(2):148-54. 
18. Jones H, George K, Edwards B, Atkinson G. Is the magnitude of acute post-exercise hypotension mediated by exercise intensity or total work done? Eur J Appl Physiol. 2007;102(1):33-40.

19. Fisher MM. The effect of resistance exercise on recovery blood pressure in normotensive and borderline hipertensive women. J Strength Cond Res. 2011;15(2):210-16.

20. Figueiredo T, Willardson JM, Miranda H, Bentes CM, Reis VM, Simão R. Influence of Load Intensity on Postexercise Hypotension and Heart Rate Variability after a Strength Training Session. J Strength Cond Res. 2015; 29(10):2941-8

21. Ruiz RJ, Simão R, Saccomani MG, Casonatto J, Alexander JL, Rhea M, et al. Isolated and combined effects of aerobic and strength exercise on postexercise blood pressure and cardiac vagal reactivation in normotensive men. J Strength Cond Res. 2011;25(3):640-45.

22. Pescatello LS, Fargo AE, Leach CN, Scherzer HH. Short-term effect of dynamic exercise on arterial blood pressure. Circulation. 1991;83(5):1557-1561.
23. Kenney MJ, Seals DR. Post-exercise hypotention: key features, mechanisms, and clinical significance. Hypertension. 1993;22(5):653-664.

24. Rezk CC, Marrache RC, Tinucci T, Mion DJ, Forjaz CL. Post-resistance exercise hypotension, hemodynamics, and heart rate variability: influence of exercise intensity. Eur J Appl Physiol. 2006;98(1):105-112.

25. McCaulley GO, McBride JM, Cormie P, Hudson MB, Nuzzo JL, Quindry $J C$, et al. Acute hormonal and neuromuscular responses to hypertrophy, strength and power type resistance exercise. Eur J Appl Physiol. 2009;105(5):695-704

26. Stephannie SB. Comparação de efeito do período de recuperação da fadiga muscular no andar entre adultos jovens e idosos. Dissertação (Mestrado em Educação Física) - Universidade Estadual Paulista. Rio Claro,2015.

27. Izquierdo M, Ibañez J, Calbet JA, González-Izal M, Navarro-Amézqueta I, Granados C, et al. Neuromuscular Fatigue after Resistance Training. Int J Sports Med. 2009;30(8):614-23 